\title{
Synergico: a new "Design for Energy Efficiency" Method enhancing the Design of more environmentally friendly Electr(on)ic Equipments
}

\author{
Lucie Domingo ${ }^{1}$, Damien Evrard ${ }^{1}$, Fabrice Mathieux ${ }^{1}$, Guillaume Moenne-Loccoz ${ }^{2}$ \\ ${ }^{1}$ Laboratory G-SCOP, University of Grenoble, Grenoble, France \\ ${ }^{2}$ Neopost Technologies, Bagneux, France
}

\begin{abstract}
One strategy to face the challenge of energy consumption has been the promotion of more efficient products and infrastructures. For the electr(on)ic industry, in-use energy consumption is a significant contributor to environmental impacts of a product lifecycle. Synergico is a contribution to the Design for Energy Efficiency of electr(on)ic equipments focusing on the use phase. This paper presents one of the Synergico tools that verifies that a higher in-use energy efficiency indeed decreases the environmental impacts of the product lifecycle and our method to be articulated with corporate design processes. Both are illustrated with a case study from the industry.
\end{abstract}

Keywords:

Ecodesign, Use Phase, Energy related product.

\section{INTRODUCTION}

When assessing the environmental impacts of an electr(on)ic product through a lifecycle assessment, the energy consumption in use phase is often the main contributor to a majority of impact categories ([1-3]). Energy consumption has also been a great challenge for modern society for the last two decades. The scarcity of fuel resources and polluting means of production are serious issues that have to be dealt with. Policies and regulations both are important means to handle these problems.

The ErP - Energy-related Product - directive [4] is a response to those two challenges which aims at enabling citizens to access more environmentally friendly electric and electronic appliances and to decrease the energetic demand at the European level.

Design for Energy Efficiency - DfEE - is a way to decrease the overall energy demand of systems, such as mobile devices [5], or manufacturing processes [6]. The method we propose in this paper is a DfEE in use phase meant to contribute to the design for environment of electr(on)ic product.

This method and its tools have been developed in the framework of the Synergico (Synergy Energy Design) project. This joint project has been funded by the French Environmental Protection Agency ADEME - and is based on a partnership between two research laboratories and two industrial partners from the electr(on)ic industry: Neopost, and Sagemcom.

From this collaboration, three tools and one method have been developed:

- An indicator of energy consumption in use phase - IUE - based on the functions and components of the product. The unit used is the watt per hour over the product time of use; the tool has already been presented in [7],

- A guideline-based tool, to sort out the strategies to meet energy efficiency target of the project by criteria; the tool has already been presented in [8],

- A simplified lifecycle assessment - LCA - tool, to check that the choices made to improve the energy efficiency in use phase do not generate environmental transfers on other phases, or on other impacts.
- A method to gather the relevant information, detailing the Who?, What?, Where?, When?, Why?, How? of the design process for energy efficiency in use phase.

This paper introduces the lifecycle verification tool, illustrated by the case study of a microcontroller on a postage meter. It then presents the global Synergico design method. This section is an illustration with a proposition of integration of the Synergico method into the design procedures of Neopost, one of the leading companies in the design and manufacturing of mailing solutions (postage meters, folding inserting systems, addressing systems, etc.). Conclusions are finally presented.

\section{LIFECYCLE CHECK TOOL}

A Lifecycle Assessment, as defined in the ISO 14040 [9], is useful to assess the environmental impacts of a product during its lifecycle. Since several impact categories and lifecycle phases are considered, it is possible to compare two products with similar functions and to identify impact tradeoffs.

The central specification for our simplified LCA tool was to help verify that the design of implemented solutions for energy efficiency in the product actually implies a better environmental performance. It is meant, as required for example by the ISO 14062 [10], to confirm that the modifications made to improve the energy efficiency do not generate unexpected additional environmental impacts on any other lifecycle stages or on any other environmental impacts.

\subsection{Environmental Impact of solutions for Energy Efficiency}

In order to have an overview of the best available and non-available technologies for energy efficiency, we based our list of solutions on the analysis of the preparatory studies for the development of specific ecodesign requirements for the ErP directive [4]. The sixth task of those reports is dedicated to viable technologies for the improvements of energy efficiency of the product category under study. The review was based on the following product categories: Boilers and Combi-boilers (Lot 1), Personal Computers and Computer monitors (Lot 3), Imaging equipment (Lot 4), Televisions (Lot 5), Stand-by and off modes losses of EuPs (Lot 6), Battery chargers and external power supplies (Lot 7), Tertiary Lighting (Lots 8-9), Electric Motors (Lot 11), Commercial and Domestic 
refrigerators and freezers (lots 12-13), Domestic dishwashers (Lot 14) and Complex Set top boxes (lot 18).

We then classified the solutions into three categories according to the following hypotheses in order to simplify the tool:

- Impact transfers are caused by physical changes in the components, hence software modifications are not supposed to imply any impact transfers;

- New technologies will not be assessed by the tool due to the confidentiality or the lack of available information;

- The suppression of a component leads to a reduction of the product impact.

In this classification, we sorted the solutions in two categories whether it is a solution with a:

- "Need to be assessed for impact transfers": the solution for energy efficiency seems to generate an impact transfer toward another impact category, another lifecycle phase or another part of the product

- "No need to be assessed for impact transfers": the solution for energy efficiency does not seem to generate an additional environmental impact on another impact category, another lifecycle phase or another part of the product.

\section{Need to be assessed for impact transfers:}

1. Changes in material, coating or manufacturing shaping: mostly for insulation, heat dissipation material, coating or shaping can be modified.

2. Component inclusion: the addition of electronic components which enable a better, finest control of product energy consumption.

\section{No need to be assessed for impact transfers:}

3. Software insertion: the addition of software code to manage the energy or to communicate information to the user is a common practice for energy efficiency. We stand that this kind of improvement will generate few or no impact transfers.

4. New technology: more efficient technologies are developed continually. Nevertheless, modelling their environmental impact is difficult due to the confidentiality or the instability of the techniques [11]. For that purpose, if a new technology is used to enhance the energy efficiency, its environmental impact calculation will not be supported by our tool.

5. Component suppression: unnecessary components might be implemented on some products. Their suppression will not generate additional environmental impacts.

Table 1: Classification of the solutions for the lifecycle check tool.

A classic problem in integrated design is to handle tradeoffs between different design objectives: energy efficiency often needs for example to be balanced with manufacturing costs or user safety. A similar issue applies in lifecycle assessment. Choices are difficult to make when there are many indicators to weigh the pros and cons. To overcome this problem, we had to limit the number of indicators in our tool. Nevertheless, those few indicators had to be representative of usual impact transfers for the categories 1 and 2 defined above.

To select the right indicators, we explored the subject of the environmental impact of electronic products while resorting to three different approach angles.
The first one was based on a general assessment of products in Europe [12]. It showed that the influence of electr(on)ic goods was significant on two indicators: on non-renewable resources depletion and energy consumption (as well as a correlated impact: global warming).

The second one focused on literature about the environmental assessment of electr(on)ic products, to reveal a pattern in the types of indicators and was based on the result of joint initiatives between governmental bodies and industrials from the electr(on)ic sector. Two projects, in Denmark [13] and in France [14], were of particular interest. Even if their goals were different, their conclusions on the most interesting indicators to follow were the same. According to these studies, the most appropriate indicators to assess [13] and to communicate [14] on environmental impacts are related to two environmental issues: energy consumption and non-renewable resources depletion over the entire lifecycle.

The third one was based on the Synergico assessment of a solution implemented for energy efficiency by our industrial partner: a microcontroller, which is an electronic component. The impact assessment of this component was done using SimaPro V7.1 with Ecolnvent Lifecycle Inventory database and evaluated according to the commonly used methods: Eco-indicator $99 \mathrm{E}$ (Figure 1: Environmental impacts of the microcontroller lifecycle with Eco Indicator $99 \mathrm{E}$ ) and the CML 2 baseline 2000 (Figure 2). This modelling helped highlight the most relevant impact categories for this component, therefore we considered it as representative for other electronic components.

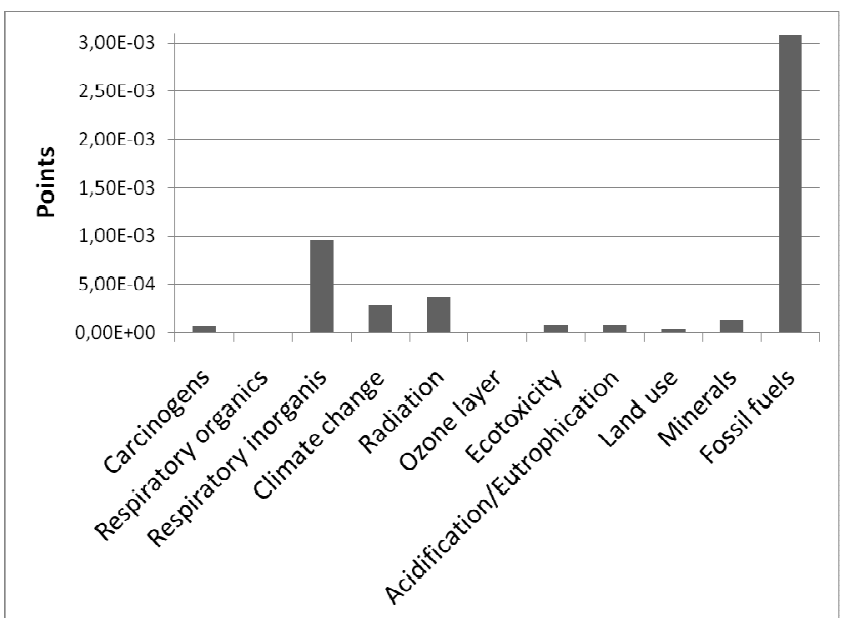

Figure 1: Environmental impacts of the microcontroller lifecycle with Eco Indicator $99 \mathrm{E}$.

Figure 1: Environmental impacts of the microcontroller lifecycle with Eco Indicator $99 \mathrm{E}$ shows that the main impacts of the microcontroller are on fossil fuels, respiratory inorganics, radiation, climate change, and minerals. The last one of this list can be described by the category "raw material depletion". The contribution to fossil fuels, climate change and radiation comes from the energy production. 


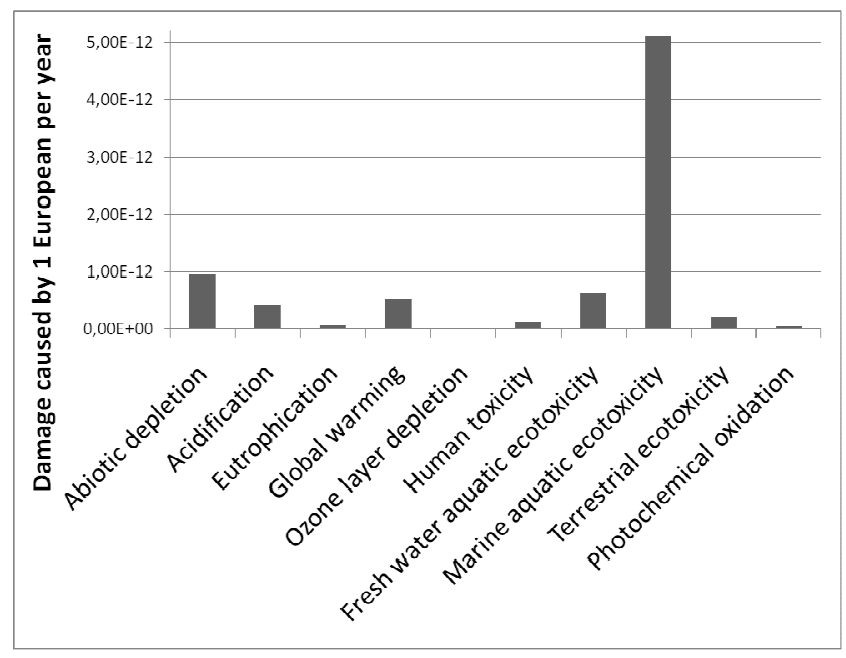

Figure 2: Environmental impacts of the microcontroller lifecycle with CML 2 baseline 2000 .

In Figure 2, the main impacts are marine aquatic ecotoxicity, Abiotic depletion, fresh water aquatic ecotoxicity, global warming, and acidification.

The lifecycle of the microcontroller highlighted the influence of the following impacts:

\section{- Toxicity (Eco- and Human) \\ - Acidification \\ - Abiotic resources depletion / Raw material depletion \\ - Global warming / Climate change}

After a concertation with our industrial partners, we decided not to consider the toxicity impacts because they are already taken into account in both the RoHS and the REACH directives. As for the acidification impact for which transportation is the main contributor and is very low if reported to the functional unit considered in the study of the whole product.

Finally, to keep a simplified tool, it appeared that two impact categories were actually significant for our purpose.

All those approaches pointed out two environmental issues that are significantly influenced by the addition of solutions for energy efficiency such as the addition of electr(on)ic: raw material depletion and energy depletion (which reflects global warming).

\subsection{Simplified LCA-based tool to be used during design for supporting design activities}

This tool is meant to assess a product or a module in its earliest stages of design when the information on the product lifecycle is still incomplete. Simplified LCA approaches are based on different assumptions: [15] proposed to group a product and its components according to their material and energy efficiency in order to support environmental decision making in the early stages of the design process. Other simplified LCA propose excluding phases with nonsignificant contribution to the entire lifecycle [16]. Our approach is based on a combination of these two approaches: finding the most relevant information on environmental impact for designers (see paragraph 2.1) and restricting the number of information to be used in the model.

The most reliable available information is about the physical architecture of components and previous or concurrent products with a similar lifecycle. This is why we decided to quantify environmental impact transfers based on:
- A comparison with a base case product, in order to plot a result based on understandable references

- A raw modelling of the component architecture to be implemented.

For each component, we predefined scenarios for the phases which are difficult to assess during design, namely distribution and end-oflife [17]. For the use phase, we modelled it as the energetic gain generated by the implemented architecture. This last value can be obtained in the IUE tool (Indicator for in-Use Energy Consumption) [7]. The recycling phase includes the recovery of materials such as precious metals which enables the saving of primary raw materials.

In order to simplify the model, each electronic component has been associated with a soldering process and a piece of electronic board and each material is linked to a shaping process.

The following section shows the input information needed to assess the environmental transfers generated by the implementation of a microcontroller on a postage meter.

\subsection{Application to the case study of the microcontroller on a postage meter}

The available data for the modelling of the microcontroller were: the architecture of such a component and the potential savings of this solution. In this case study, the microcontroller was used to influence the energy consumption in standby mode, hence a gain of $7.5 \mathrm{~W}$ with the same level of performance for the product by adding a card of $2.25 \mathrm{~cm}^{2}$.

First, we chose the product architecture that represented the best the actual product design. Secondly, the modelling of the components of the microcontroller was done. Thirdly, the amount of energy saved over the product use-time by this solution was documented (in kWh).

After modelling the data, the assessment was carried out. Figure 3 shows the comparison between the environmental impacts of the base case product and the under-design product.

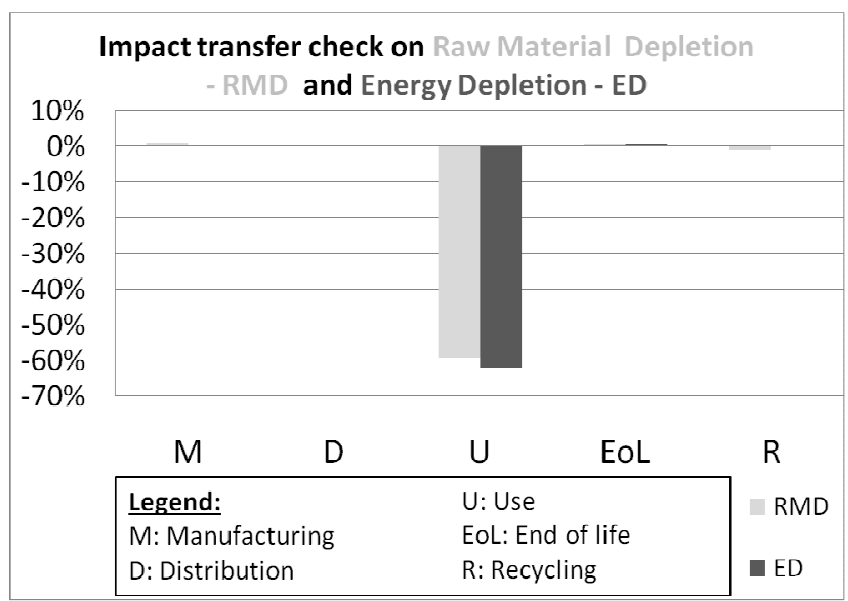

Figure 3: Result of the assessment of the impact transfers for the microcontroller implemented on a postage meter.

For the manufacturing and the end-of-life phases, the new product has slightly higher impacts of about $1 \%$, for both raw material depletion and energy depletion.

The contribution of the microcontroller on raw material depletion during recycling is negative because of the increase of potentiality for recycling due to the addition of the microcontroller, which means that the new design has a better performance than the base case study. It is all the more visible during the use phase with both 
impact categories around $-60 \%$, which overcomes the loss of performance during the manufacturing and the end of life.

The largest contribution is generated by the saved energy thanks to the microcontroller.

The suggested lifecycle check tool is not meant to replace an LCA but to support designers in a rapid way for analyzing the environmental impacts of the product architecture. Therefore, it can be viewed as an alternative to a full lifecycle assessment when a comparison between energy savings and the addition of components is needed during design.

\section{SYNERGICO METHOD: INTEGRATING THE TOOLS INTO THE PRODUCT DESIGN PROCESS}

In order to drive the tool described above and the other two tools developed for this project [7], [8], the Synergico method has been written as a means to support the design management in the implementation of the tools in the design process by specifying the Who?, What?, Where?, When?, Why?, How? of the tools.

\subsection{Design process of electr(on)ic products}

A preliminary condition to define a design method is to observe and to identify the form of the actual design process for the development of electr(on)ic products.

Various design processes exist and many companies have their own procedure. One of our objectives was to ensure the compatibility of the Synergico method with the corporate design processes.

Our choice had been to base our work on existing generic models for product development like [10], [18]. We then assessed their compatibility with the design process used by our industrial partners and [10]. Eventually, we chose the most appropriate form of process with the following steps: Planning, Preliminary design, Detailed design, Test, Industrialization. Those design steps define the milestones of the method and will be the five values that the When? can take.

The chosen design process is linear [Figure 5] with no possibility to go back to previous steps, since we considered in the method, that the design steps are milestones and Synergico helps validate a step before entering to the following one.

To define Who?, our approach has mostly been based on the departments implied in the design activities of our partners. Seven different competences were identified in the following departments:

- Electronic design: in charge of the design of the boards, their drivers, power supplies and all other electronic components,

- Mechanical design: in charge of the design of the kinematic sets (engines, actuators, sensors...) and the structure of the product (shell...)

- Software design: in charge of the software coding and its implementation on the hardware structure

- Project management: managing the different actors of the design project, fulfilling the objectives and coordinating the relations between the different departments

- Marketing: in charge of the interface between client and design team by means of specification and product requirements.
- Purchase: in charge of finding the adequate suppliers for components, materials, machinery, etc. according to project management specifications

- Ecodesign expertise: in order to go deeper in the DfE, such an expert may be useful.

In order to simplify Figure 5, we used in this paper only two actors, namely the "designers" (electronic, mechanical, and software design) and the "transverse functions" (project management, marketing, purchase, and ecodesign expertise).

To define Where?, a list of the key "places" in the Synergico toolbox was defined: Lifecycle Check Tool, Guidelines, Indicator of in-use energy consumption, Specification, Functional splitting, Physical splitting, Use scenario, Power. We named those "places" sub-tools.

\subsection{Integration of the tools in the design process}

The What?, Why?, How? are highly dependent on the tool we consider.

In Synergico, What? refers to the input data to be processed at this stage, Why? refers to the expected results, i.e. the output and How? refers to the way the input data are processed to obtain output data.

The structure of the method is defined in two diagrams with the same axes: the different sub-tools (Where?) and the steps of the design process (When?). The first one presents the actors (Who?) (Figure 5) and in the second one, which is not illustrated in this article, the data flows (What? and Why?).

The association of a design process step with a sub-tool defines what we call a "block". For each block, the method specifies Who?, What?, Where?, When?, Why?, How?, which correspond to the input / output data, the actors involved at this step whose skills are needed to fill in the tools. The Synergico method is composed of 23

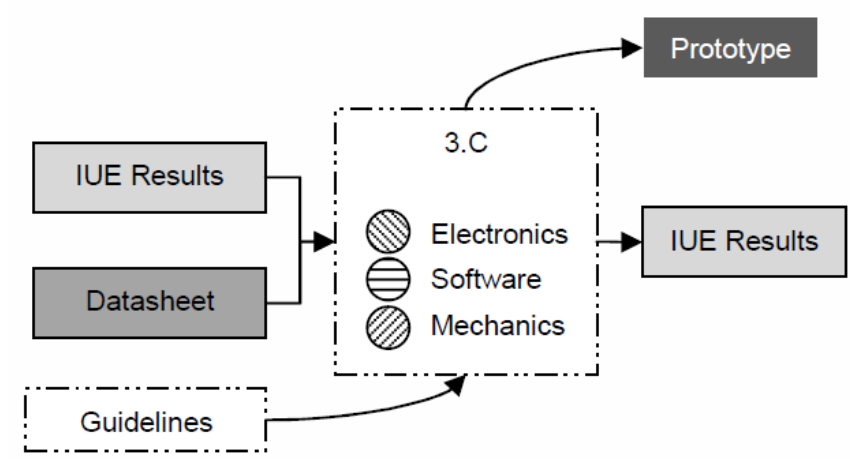

blocks indexed according to the design stage and the sub-tool considered.

For example, the block 3.C (Figure 4) represents the sub-tool "power" during detailed design.

In this case, the input data are the IUE results from the power subtool and the datasheets of the components providing information about the power they require. The electronic, software and mechanical departments are the ones involved in this step. They can use the help of the Guidelines tool to drive the design of the prototype. The outputs are new specifications for a prototype and new IUE results.

Figure 4: Block 3.C Power during detailed design. 


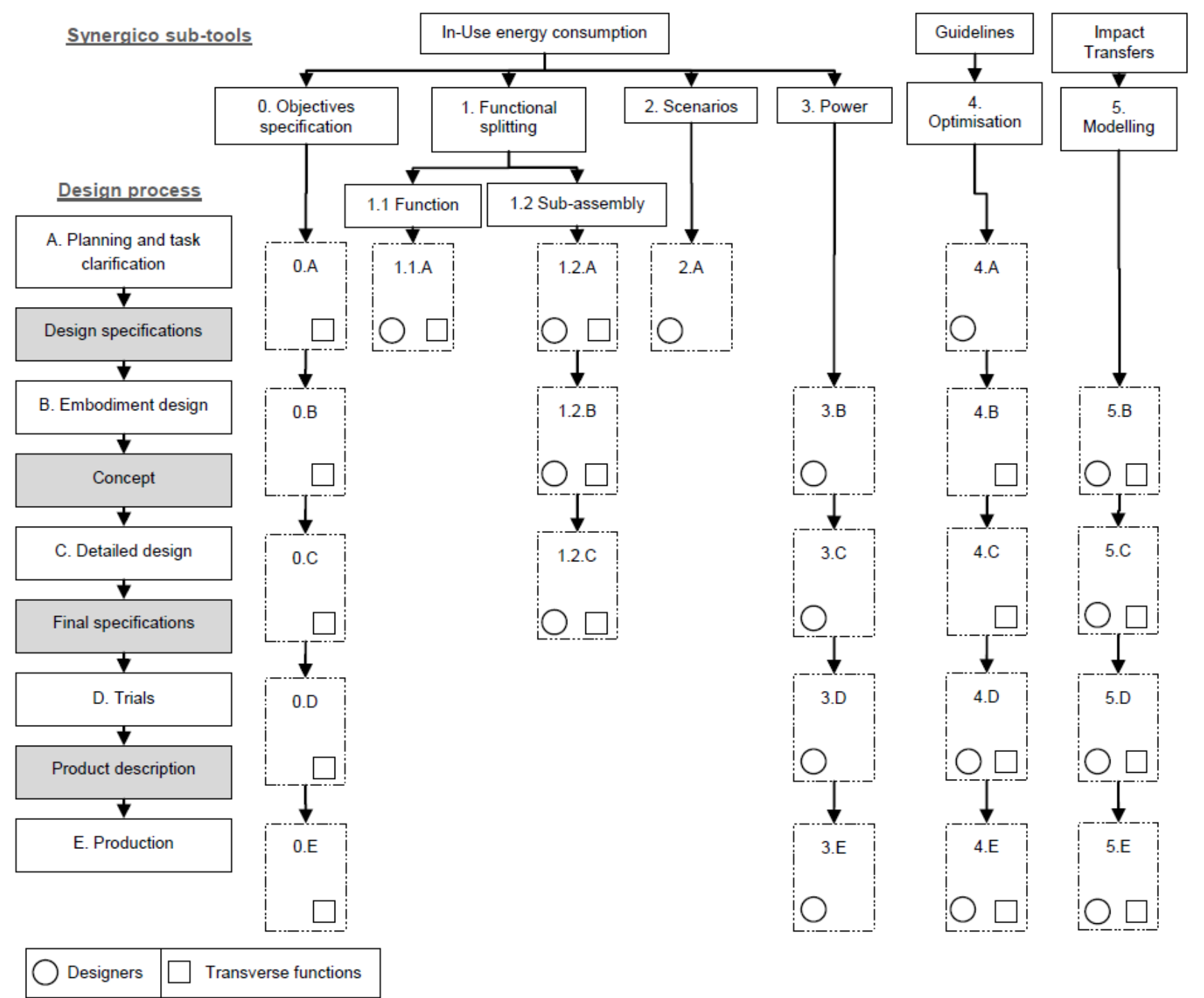

Figure 5: Articulation between Synergico, the design process and the actors of the project.

\subsection{Implementation at Neopost}

Once we had defined a generic method, some adjustments had to be done to fit in the design process of our project partners. This section presents the integration of Synergico in the design process of Neopost.

This part of the project involved the corporate Quality,Health, Safety \& Environment manager and the Ecodesign Expert.

The first step was to adjust the general method to the actual practices of Neopost and especially, an adaptation of the vocabulary used in the method and tools has been necessary. Thus, the generic terminology was adapted to the one currently used in the company concerning the departments and the design phases.

The second step consisted in specifying the interaction of the Synergico tools with other Neopost's design practices, tools and methods in terms of:

- Where to find the external input information?

- Where to use the external output information?
We defined, as external input, data such as the information contained in the customers' requirements and the capitalization data. During the implementation process we defined who, in a design project team, was the most adequate department or person to provide such information and to mediate its use in the design process.

We defined, as external output information, the results of the InUse-Energy consumption indicator, for example. The aim of the implementation was to define how this data can be used outside design to support communication and marketing experts.

After adapting and connecting Synergico with other design procedures of Neopost, Design for Energy Efficiency was integrated in Neopost strategy as part of the tool kit for integrated design of postage meters.

\section{CONCLUSIONS}

This paper presents a tool whose purpose is to validate, from a lifecycle perspective and considering two impacts, the modifications of an electr(on)ic product during its design or redesign in order to increase its energy efficiency. It also introduces the method 
developed to coordinate the tools indicator for In Use energy consumption [7], Guidelines [8], and Impact transfers.

As stated earlier, energy efficiency in use is a central issue for electr(on)ic products and their environmental performances can be highly modified by decreasing their energy consumption. It is the reason why considering this aspect as early as possible in the design process is essential. Synergico method is aimed at driving design toward a more efficient product in use phase by providing a step-by-step methodology based on three complementary specifically tailored for the design process of electr(on)ic equipments.

The proposed case study happened during the redesign of a product and, in order to validate the Synergico method, the implementation of the method and tools.

The collaboration with both industrial partners, Neopost and Sagemcom, a manufacturer of telecommunication equipments, has been essential to insure the practicability and relevance of the tools and method for the electr(on)ic industry. Further developments are ongoing to improve the reliability of the tools and to make them robust enough to be used by the whole sector of electr(on)ic equipments.

In order to verify the universality of the method, other applications with other industrial partners will be carried out. A new manufacturer has already been identified to test the Synergico method from the early stages of the design of a new electr(on)ic product to its final market launch.

\section{ACKNOWLEDGMENTS}

We acknowledge the financial support of the French EPA ADEME (Contract \#0877C0032) in the framework of the 2008 call for proposal on "Research,development and innovation in Ecodesign."

We also want to thank our industrial partners and especially, the entire design team at Neopost Technologies that collaborated in the construction of the Synergico method and tools.

\section{REFERENCES}

[1] Junnila S. (2008): Life cycle management of energyconsuming products in companies using IO-LCA, in: The International Journal of Life Cycle Assessment, vol. 13, n: 5 , p. $432-439$

[2] Kim S., Hwang T., Overcash M. (2001): Life cycle assessment study of color computer monitor, In: The International Journal of Life Cycle Assessment, vol. 6, $\mathrm{n}^{\circ}$. 1, p. 35-43.

[3] Muñoz I., Gazulla C., Bala A., Puig R., Fullana P. (2008): LCA and ecodesign in the toy industry: case study of a teddy bear incorporating electric and electronic components, In The International Journal of Life Cycle Assessment, vol. 14 n. 1, p. 64-72.

[4] European Commission (2009): DIRECTIVE 2009/125/EC establishing a framework for the setting of ecodesign requirements for energy-related products.

[5] Heath T., Pinheiro E., Hom J., Kremer U., Bianchini R (2004): Code transformations for energy-efficient device management, In: Computers, IEEE Transactions on, vol. 53 , n. 8, p. 974-987.

[6] Rahimifard S., Seow Y., Childs T. (2010): Minimising Embodied Product Energy to support energy efficient manufacturing, In: CIRP Annals - Manufacturing Technology, vol. 59, no. 1, p. 25-28.
[7] Domingo L., Mathieux F., Bonvoisin J., Brissaud D. (2010): Indicator for in Use Energy Consumption (IUE): a tool enhancing Design for Energy Efficiency of products, In IDMME - Virtual Concept 2010

[8] Bonvoisin J., Mathieux F., Domingo L., Brissaud D. (2010): Design for energy efficiency: proposition of a guidelinesbased tool, In International Design Conference- Design 2010 .

[9] International Standard Association (2006): ISO 14040: Life cycle assessment, principle and framework.

[10] International Standard Association (2003.): XP ISO/TR 14062: Environmental management -- Integrating environmental aspects into product design and development.

[11] European Commission (2006): Proceedings of the Workshop on Nanotechnology and Life Cycle Assessment.

[12] Tukker A., Jansen B. (2006): Environmental Impacts of Products: A Detailed Review of Studies, In: Journal of Industrial Ecology, vol. 10, n. 3, p. 159-182.

[13] Institute for Product Development DTU Denmark, Danish Toxicology Center (2005): Eco-conscious design of electrical and electronic product.

[14] ADEME, AFNOR (2010): Environmental label of consumer market's product.

[15] Kaebernick H., Sun M., Kara S. (2003): Simplified Lifecycle Assessment for the Early Design Stages of Industrial Products, In: CIRP Annals - Manufacturing Technology, vol 52, n. 1 , p. 25-28

[16] Hur T., Lee J., Ryu J., Kwon E. (2005): Simplified LCA and matrix methods in identifying the environmental aspects of a product system, In: Journal of Environmental Management, vol. $75, n^{\circ} .3$, p. $229-237$

[17] Nielsen P. H. , Wenzel H. (2002): Integration of environmental aspects in product development: a stepwise procedure based on quantitative life cycle assessment, In Journal of Cleaner Production, vol. 10, n. 3, p. 247-257.

[18] Pahl G., Beitz W., Wallace K., Feldhusen J., Blessing L.( 2007): Engineering design, In: Springer. 